\title{
THE CREDIT RISK DYNAMICS OF INTERNATIONAL BONDS: THE INDONESIAN CASE
}

\author{
Kannan S. Thuraisamy ${ }^{1}$ \\ ${ }^{1}$ Department of Finance \& Centre for Financial Econometrics, Deakin Business School, Faculty of \\ Business \& Law, Deakin University, Victoria, Australia. \\ Email: sivananthan.thuraisamy@deakin.edu.au
}

\begin{abstract}
The objective of this paper is to test how market-determined local-, global- and USbased factors explain the behaviour of Indonesian credit spreads. Using a specific asset class of bonds issued in the international market by the Indonesian government, this paper provides evidence confirming the importance of major local and global macroeconomic variables in pricing risky debt issued by Indonesia. Using US dollardenominated bonds ranging from shorter- to longer-maturity groups, this study provides insights into the role of these determinants in the pricing process. Given the implications for pricing and risk management, the evidence from this study is important for investors, policymakers, and issuers.
\end{abstract}

Keywords: Credit spread; Indonesia; International bonds.

JEL Classification: C5; E1.

Article history:

Received : July 15, 2018

Revised : October 2, 2018

Accepted : December 16, 2018

Available online : January 31, 2019

https://doi.org/10.21098/bemp.v0i0.980 


\section{INTRODUCTION}

The market practice of pricing risky bonds involves estimation of the credit spread that accounts for the riskiness attributable to the issuer. Given the estimated spread, the yield applicable to a risk-free benchmark is added to generate the applicable yield for a risky bond. The literature has produced mixed results on the determinants of credit spread implied by structural models of default started with the seminal work of Merton (1974). The performance of market-determined variables at the global and country levels is mixed (Austin, 2018).

The purpose of this paper is to test the role of global-, local- and US-based market-determined variables in explaining the credit spreads on government bonds issued by Indonesia. Indonesian sovereign credit spreads for individual bonds are generated using a matching US benchmark with the same maturity. The difference in yield between the risky Indonesian government bond and the riskfree US matching benchmark is used as the credit spread for individual bonds to test for its determinants.

The prominence of emerging market debt as an asset class requires the development of insights into the behaviour of government bonds. Examining such instruments at the disaggregated level in a dominant emerging market that witnessed a major financial crisis in 1997 in the Asia-Pacific region is crucial to understanding how the yield spreads associated with various maturities and how they respond to variables that theoretically determine the spread.

To this end, the behavioural dynamics of Indonesian sovereign credit spreads are investigated by modelling the determinants of credit spread changes using variables derived from structural and macroeconomic theory. Such an understanding has implications for pricing and portfolio decisions. Insights into the behaviour of existing instruments is also likely to aid policy decisions by central banks when it comes to issuing new instruments in the international market for state financing.

With this aim, we use a clean segment of the bond market: sovereign bullet bonds denominated in US dollars (USD) issued by Indonesia. We generate the credit spreads associated with these bonds by using matching US benchmark bonds and test how global-, local-, and US-based variables explain the behaviour of Indonesian credit spreads differentiated only by their maturity.

Despite the notable widening of Indonesia's Current Account Deficit (CAD) in 2018, its sovereign credit rating remained BBB-, with a stable outlook. One of the primary reasons stated by the rating agency (Standard \& Poor's) for assuring a stable outlook and the BBB- rating despite worsening of the CAD in 2018 was Indonesia's low level of reliance on foreign currency debt, implying reduced vulnerabilities and the capacity for solvency. The underlying strategy is Indonesia's deliberate attempt to shift from external to domestic sources of deficit financing since 2005, with the intention of lengthening locally issued government securities to construct a yield curve (see, Bank for International Settlements, no. 67, p. 2003).

The market's perception of a country's repayment capacity is a key factor that drives the pricing of risky debt (Claessens and Pennacchi, 1996). Among other factors, the country's level of indebtedness and capacity to generate revenue are key factors that shape such a market perception and the country's rating outlook 
provided by rating agencies, ${ }^{2}$ signalling the nature of credit risk attributable to a given issuer of risky fixed-income instruments. Hilscher and Nosbusch (2010) show the effect of terms of trade on sovereign credit risk by show the statistically and economically significant effect of the volatility of the terms of trade on sovereign credit risk.

Several studies have examined the determinants of credit spread (e.g. Batten et al., 2006; Thurisamy et al., 2008; Longstaff et al., 2011; Riddle et al., 2013). They demonstrate the importance of local and global factors as determinants of credit spreads in sovereign settings. On the other hand, Collin-Dufresne et al. (2001) and Avramov et al. (2007), among others, demonstrate how structural model variables explain credit spread dynamics in corporate settings. We closely follow CollinDufresne et al., Avramov et al., and Longstaff et al. (2011) in choosing global-, local-, and US-based market-determined variables to test the determinants.

As outlined previously, the motivation for this study is to understand the behaviour of Indonesian credit spreads and the extent to which market-determined variables explain them. The asset price dynamics at the individual bond level captured by Figure 1 depict the behaviour of yield spreads and bond returns and the divergent behaviour of bonds issued by a single sovereign entity differentiated only by maturity. Essentially, this study contributes to understanding the pricing mechanism associated with sovereign bonds issued by Indonesia in international markets by investigating the following research questions:

i) Are the Indonesian credit spreads of international bonds responsive to the popular determinants derived from structural models of credit risk?

ii) If so, how consistent are these credit spreads across different maturities?

To test the determinants of sovereign credit spreads, this paper applies a generalized autoregressive conditional heteroskedasticity (GARCH) process, specifically GARCH(1,1), to understand how the global-, local-, and US-based determinants explain the behaviour of Indonesian sovereign credit spreads. Briefly foreshadowing the results, this paper demonstrates the importance of global market-determined variables, such as the high-yield index and the CBOE Volatility Index (VIX), and local market-determined variables, such as the local stock market index and the exchange rate factor, in explaining the behaviour of Indonesian sovereign credit spreads across different maturities. The results are consistent with prior evidence on sovereign credit spread behaviour, such as the results of Longstaff et al. (2011) in the context of sovereign credit default swaps and Riddle et al. (2013) and Thuraisamy et al. (2008) in the context of emerging market spread determinants.

2 Indonesia's CAD widened to USD 5.5 billion in the first quarter of 2018, an increase of $129 \%$ compared to the first quarter of 2017. The deterioration of the CAD, which captures the country's global trade, was also concerning in terms of its effects on Indonesia's gross domestic product, accounting for $2.15 \%$ of it, compared to $1 \%$ a year earlier. 
Figure 1. Credit Spread and Return Relationship

Figures below depict the behaviour of individual spreads and the underlying bond return associated with the bond.

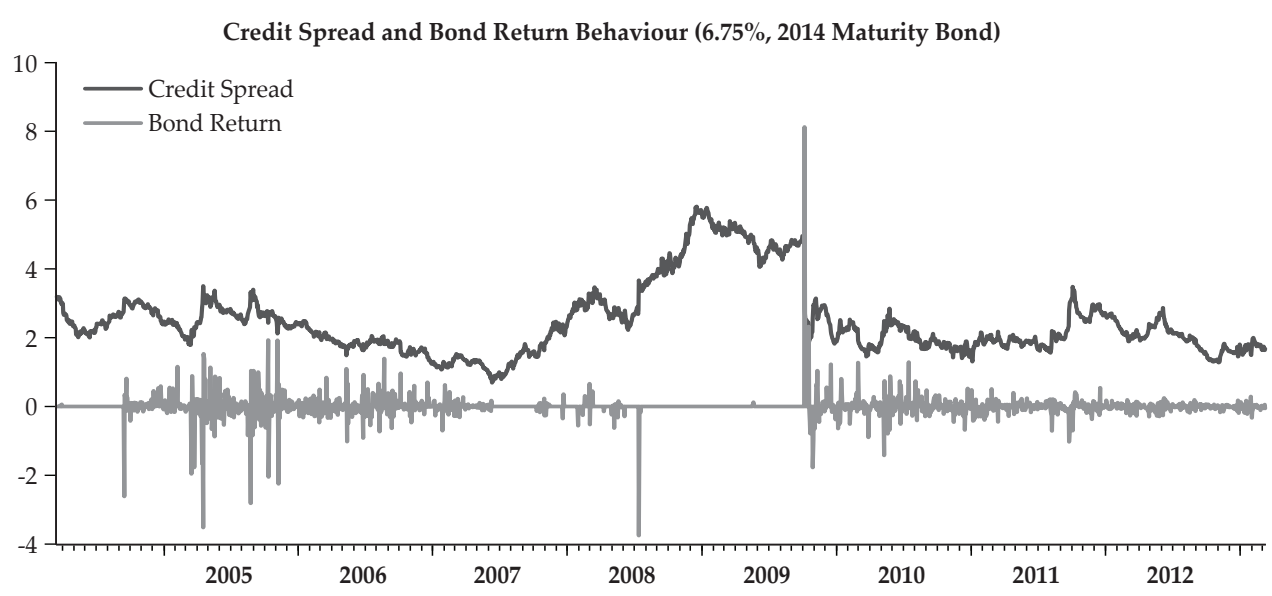

Credit Spread and Bond Return (7.25\%, 2015 Maturity Bond)

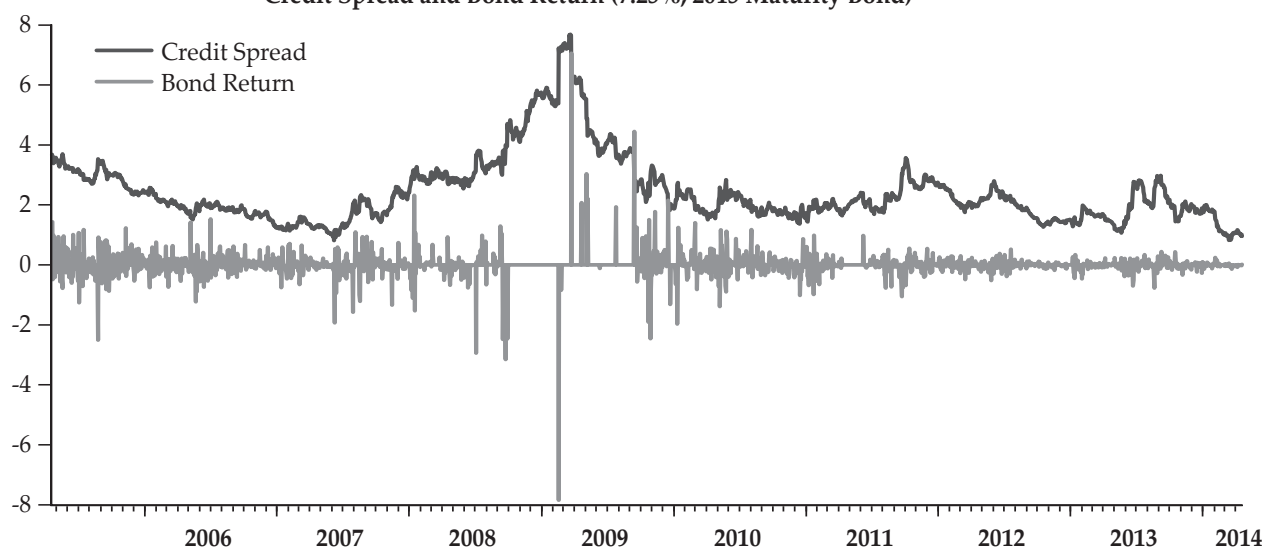

Credit Spread and Bond Return (7.5\%, 2016 Maturity Bond)

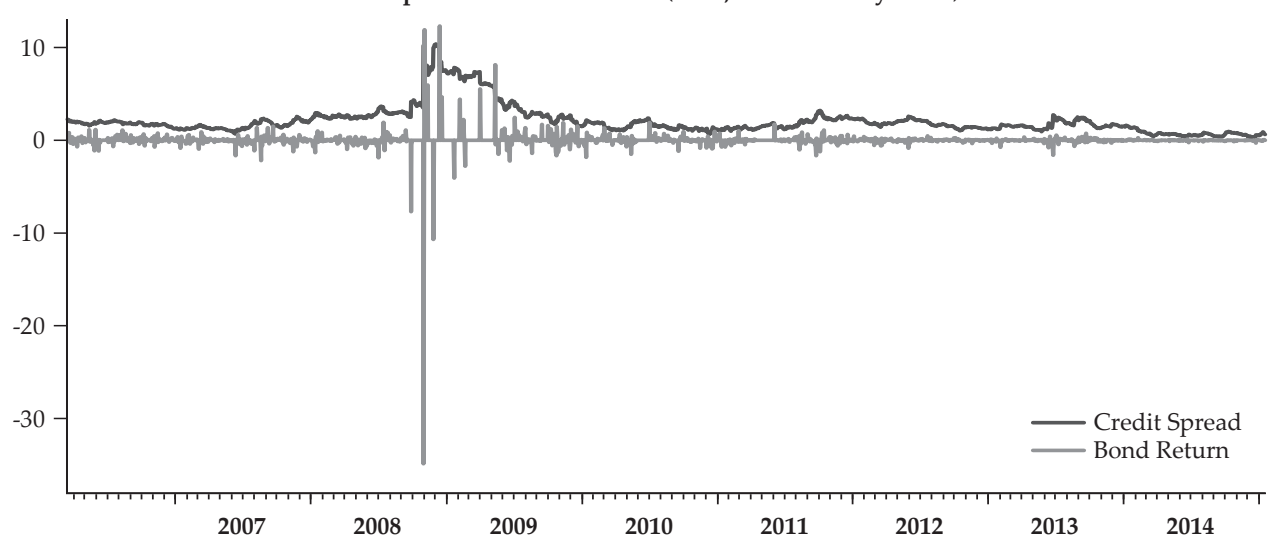


Figure 1. Credit Spread and Return Relationship (Continued)

Figures below depict the behaviour of individual spreads and the underlying bond return associated with the bond.
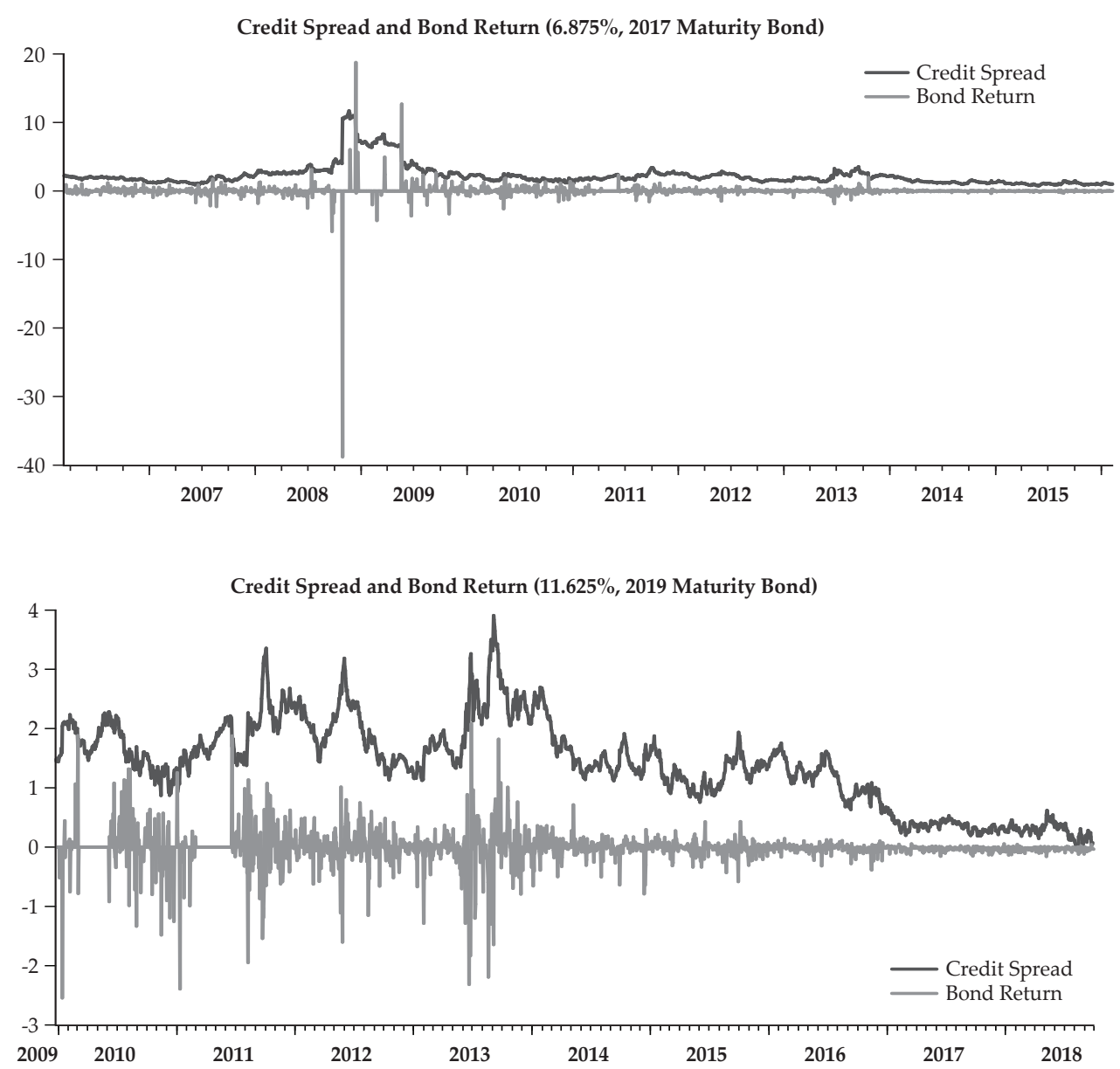

Credit Spread and Bond Return (5.875\%, 2020 Maturity Bond)

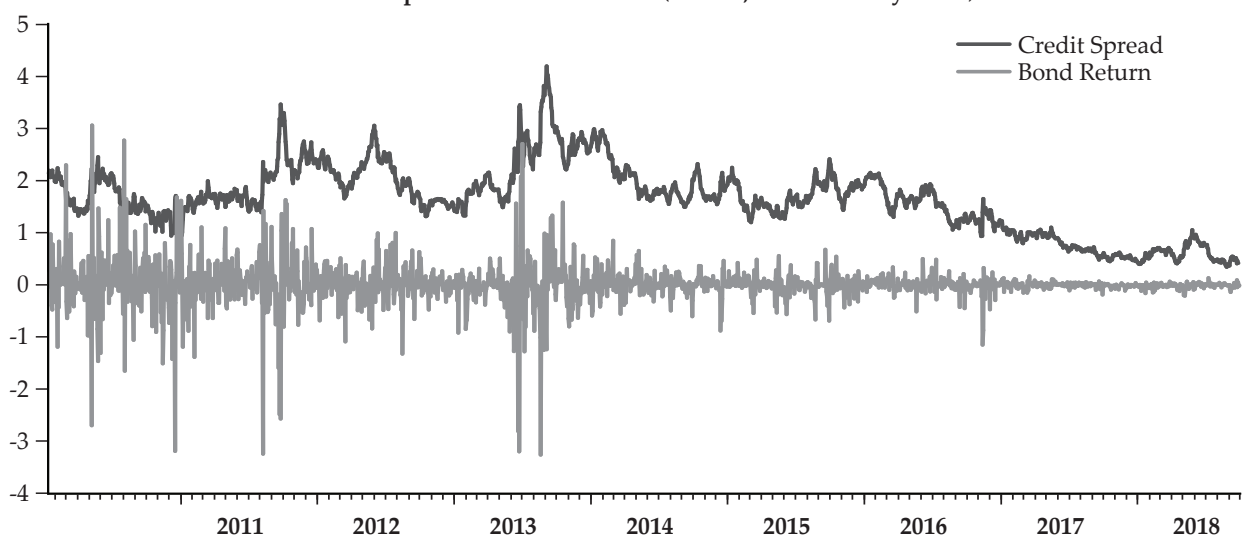


Figure 1. Credit Spread and Return Relationship (Continued)

Figures below depict the behaviour of individual spreads and the underlying bond return associated with the bond.

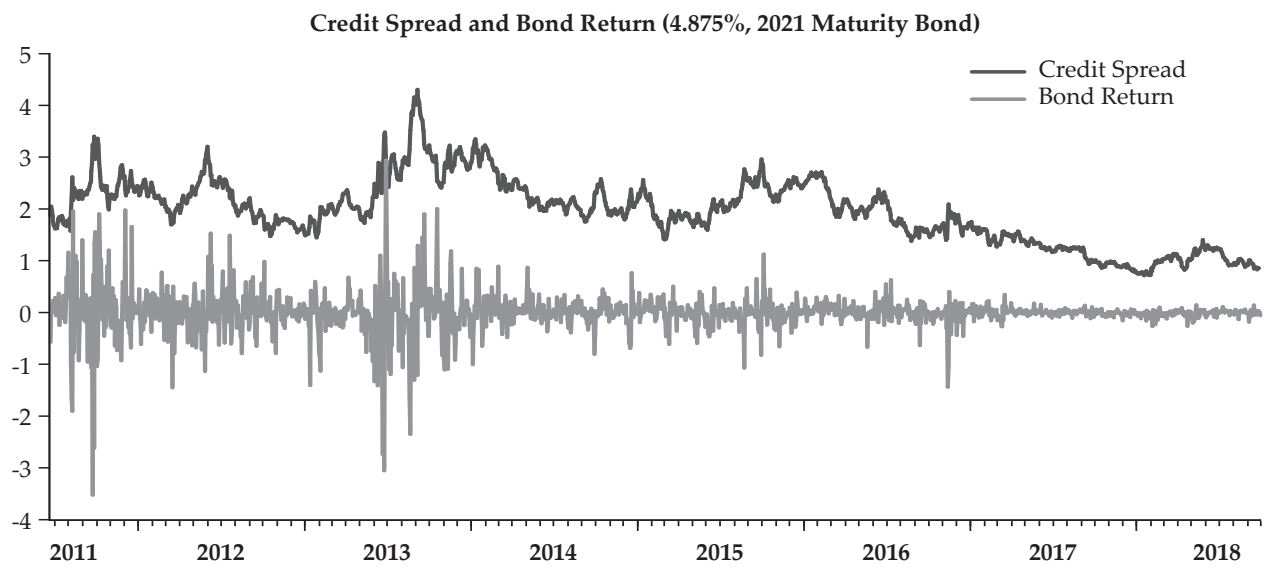

Credit Spread and Bond Return (8.5\%, 2035 Maturity Bond)
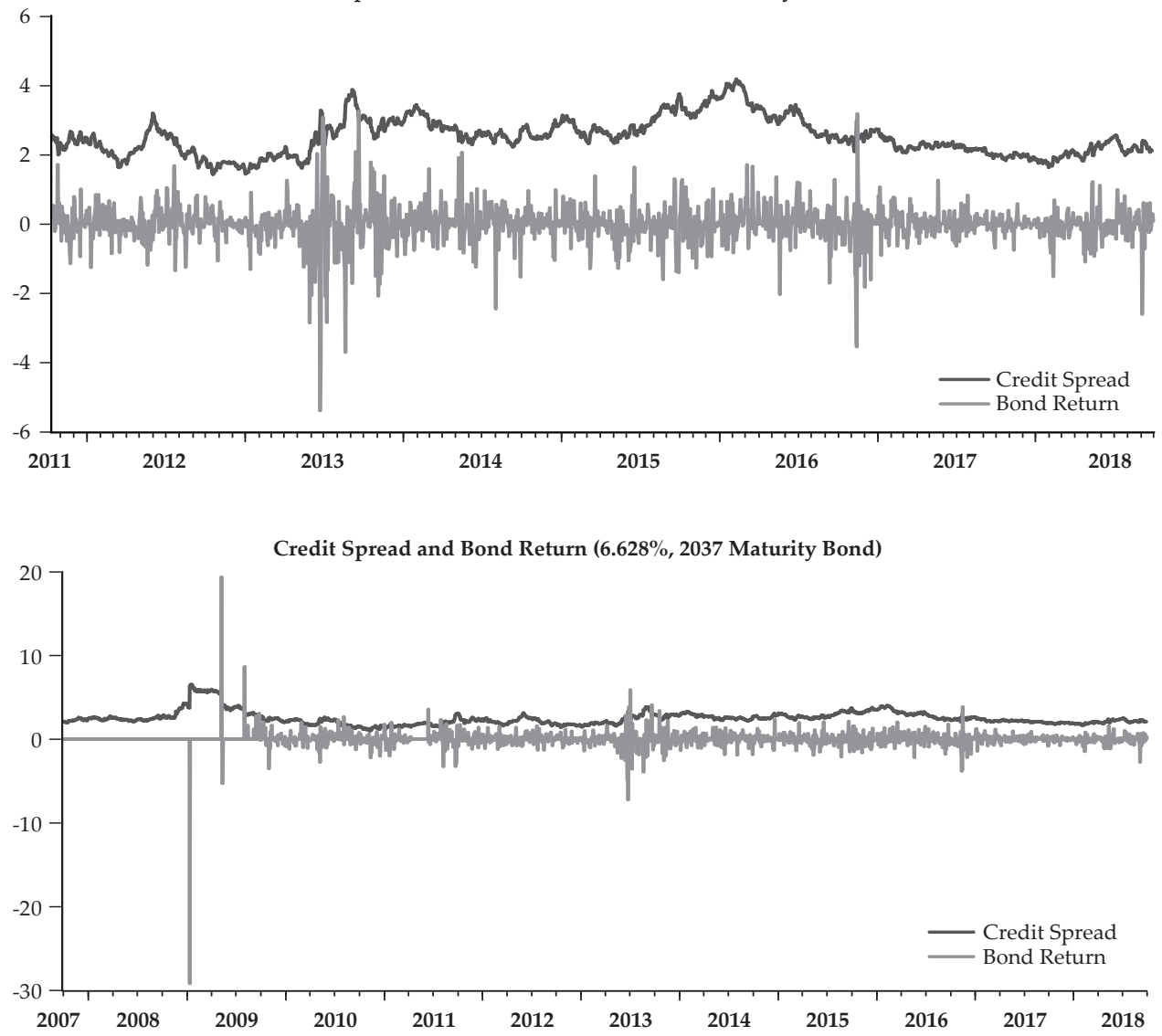


\section{DATA}

This paper examines the yield spreads of sovereign bonds issued by Indonesia in the international market. Our initial search on Bloomberg revealed 28 USDdenominated bonds issued by the Republic of Indonesia. The filtering process selected bonds with bullet features to ensure the spreads were free from embedded option factors. Further filtering for price availability yielded nine bonds with clean prices. These bonds vary in terms of maturity and are classified as short-, medium-, and long-term bonds for our analysis. To generate the credit spreads, we matched each Indonesian bond to the US benchmark bond with the closest maturity.

The sample period varies for each bond, given the time series nature of this exercise, and the details of the maturity date, coupon, and initial maturity are as follows: i) $6.75 \%$ a 10-year bond maturing 10 March 2014, ii) 7.25\% a 10-year bond maturing 20 April 2015, iii) 7.5\% a 10-year bond maturing 15 January 2016, iv) $6.875 \%$ a 10 -year bond maturing 9 March 2017, v) $11.625 \%$ a 10 -year bond maturing 4 March 2019, vi) 5.875\% a 10-year bond maturing 13 March 2020, vii) $8.5 \%$ a 30 -year bond maturing 12 October 2035 , and viii) $6.625 \%$ a 30 -year bond maturing 17 February 2037.

Now we examine salient features of the data used in this study. Based on the results reported in Table 1 on the data set used in this study, the mean spread ranges from 1.40 to 2.71 , with an associated standard deviation ranging from 0.63 to 1.59. All the spreads exhibit positive skewness and excess kurtosis. The mean yield for the individual bonds ranges between 3.32 and 6.66 and the standard deviation of the yields ranges from 0.69 to 2.47. Except for the bonds maturing in 2014 and 2015 , all the other bonds have positive skewness with excess kurtosis in the range from 1.62 to 11.97. The mean yield for the US benchmark bonds ranges between 2.0 and 3.99 and the standard deviation of the yield ranges between 0.80 and 1.74. Except for the longer-maturity bond maturing in 2036, all other benchmark bonds show positive skewness and the kurtosis values lie between 1.60 and 1.95. The figures for individual bond spreads and the returns generated by the bonds reveal price clustering, confirming autoregressive conditional heteroskedasticity effects. We utilize a GARCH $(1,1)$ process to accommodate the time-varying behaviour of the spreads associated with the bonds selected for this study. 


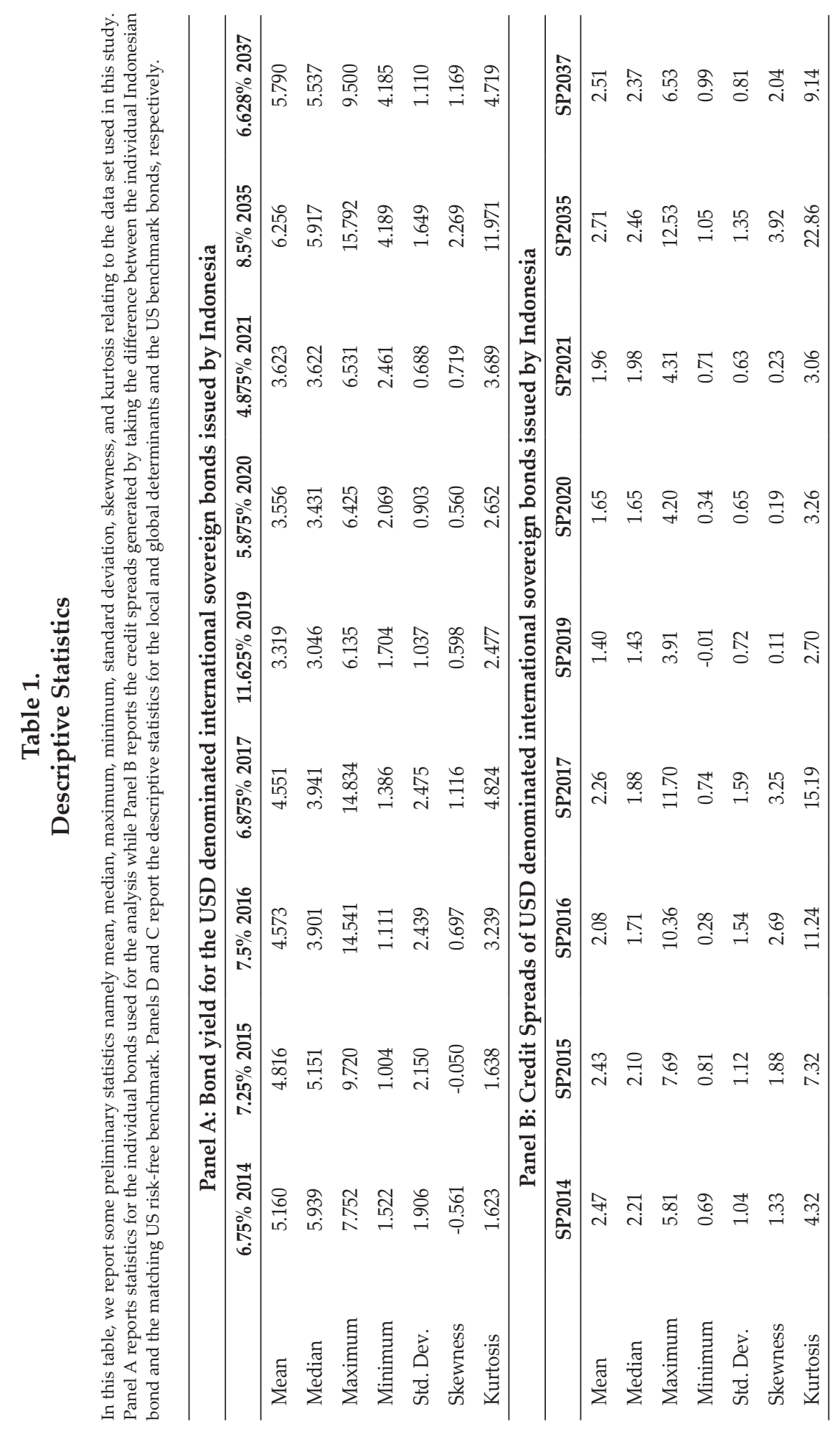




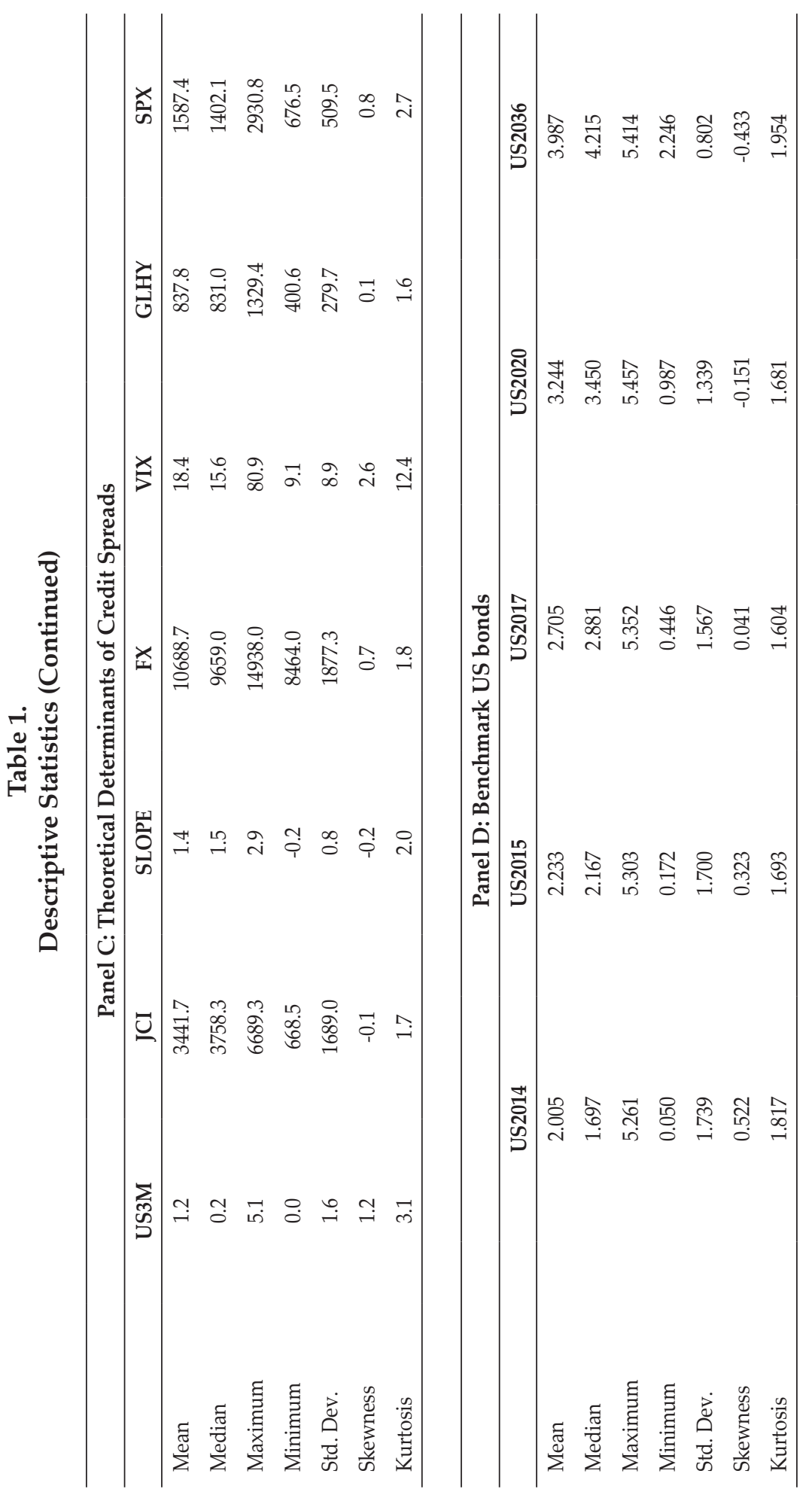




\section{METHOD}

We use structural models of credit risk to analyse the dynamics surrounding the credit spread behaviour of Indonesian bonds issued in international markets. An understanding of the specific factors driving sovereign credit spreads is fundamental to pricing decisions relating to these instruments and their derivatives. There is also a lack of understanding of the application of structural models at the country level in the Asia-Pacific region. A modified set of determinants derived from the structural models of Longstaff and Schwartz (1995) and an extended multifactor model as applied by Collin-Dufresne and Goldstein and Martin (2001) form the basis for the selection of variables, giving due consideration to Indonesia's market setting. Given the price clustering observed in Figure 1, this study employs a GARCH framework within the structural framework of default risk to account for the time-varying volatility of credit spreads.

Using the determinants of credit spread, this study estimates the following $\mathrm{GARCH}(1,1)$ regression:

$$
\begin{aligned}
\Delta C S_{t}^{i} & =a+b \Delta I_{t}+c \Delta J C I_{t}+d \Delta s \text { lope }_{t}+e \Delta F X_{t}+f \Delta V I X_{t}+g \Delta H Y_{t}+h \Delta S P X_{t}+\varepsilon_{t}, \\
\sigma^{2} & =\alpha_{0}+\alpha_{1} \varepsilon_{t-1}^{2}+\beta_{1} \sigma_{t-1}^{2}
\end{aligned}
$$

where $\Delta C S_{t}^{i}$ is the change in the yield spread for the individual government bond; $\Delta I_{t}$ is the change in the interest rate factor captured by the three-month US Treasury bill; $\Delta J C I_{t}$ is the change in the asset factor capturing the health of the Indonesian economy, using the Jakarta Stock Price Index; $\Delta$ slope $_{t}$ is the slope of the US yield curve capturing the business cycle effect; $\Delta F X_{t}$ is the exchange rate, capturing the country's risk sentiment; $\Delta V I X_{t}$ is the change in the VIX, capturing the uncertainty in the US equity market; $\Delta H Y_{t}$ is the change in the US high yield index, capturing the behaviour of risky fixed-income instruments, given the risky nature of Indonesian bonds; $\Delta F X_{t}$ is the change in the US stock market index (S\&P 500 index); and $\varepsilon_{t-1}^{2}$ and $\sigma_{t-1}^{2}$ in the variance equation are the squared residuals and lagged conditional variance, respectively.

\section{RESULTS}

The determinants of USD-denominated bonds issued by Indonesia are reported in Tables 2 and 3. As stated, this study utilizes a set of variables that theoretically determine credit risk. Deriving from structural models of default, this paper tests changes in the asset factor, the interest rate factor, the exchange rate factor, the slope of the yield curve, the VIX, the high yield index, and the US stock market index. Table 2 reports the results for the entire sample of bonds selected, grouping them as shorter-maturity, medium-term maturity, and longer-maturity bonds, respectively, in Panels A to C. The results are discussed along these maturity categories. 
A. Credit spread determinants based on maturity groups

A1 Shorter-maturity bonds: Four USD-denominated government bonds belong to the shorter-maturity category and all bonds in this category have matured in terms of remaining maturity. The interest rate factor reported in the third column of Panel A in Table 2 is significant for the two bonds maturing in 2015 and 2016 and, as expected, the signs are negative, implying the spread narrows as the riskfree rate rises. The rise in interest rate increases the risk-neutral process for the value of the issuer, exerting downward pressure on the risk-neutral probability of default (Longstaff and Schwartz, 1995). The asset factor is significant for three of four bonds in this category and the signs of the coefficients are negative, implying an increase in the value of the issuer decreases the probability that the issuer will default. The slope of the yield curve reported in the fifth column is significant only for the bond maturing in 2015 and the coefficient is negatively related to the slope variable. The exchange rate variable is significant for all bonds except for the 2014 maturity bond, potentially implying a negative impact of an appreciating currency for the Indonesian economy. 


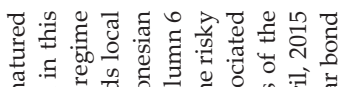

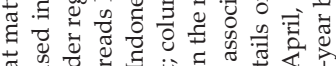

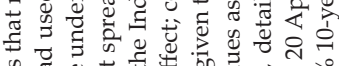

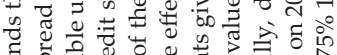
है की.

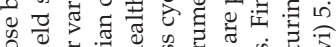

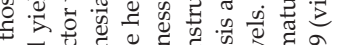

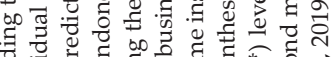

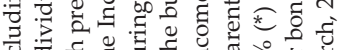

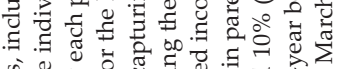
जे

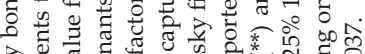

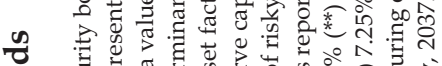

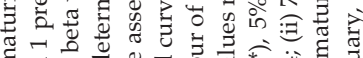

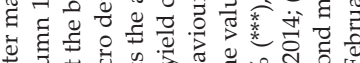

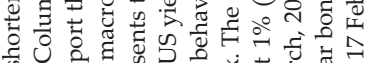

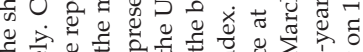
$\cong$ Ð

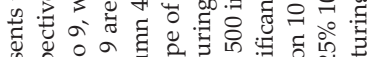
ญ की

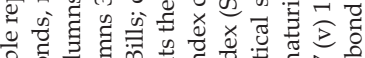
范

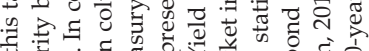

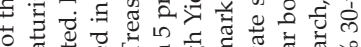

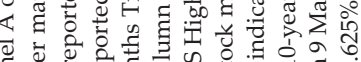
च 드은

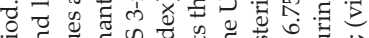

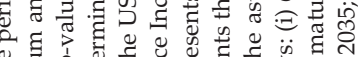

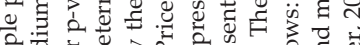

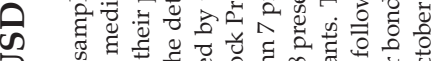
ఐ

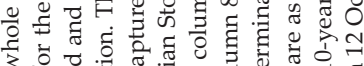

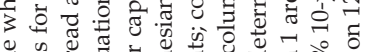

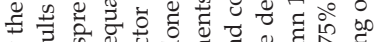

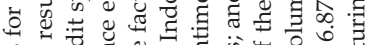

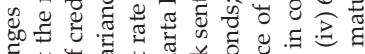

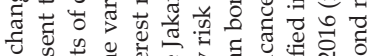

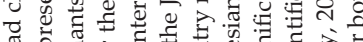

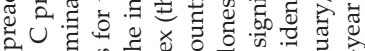

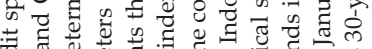
更

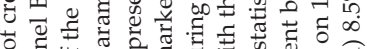

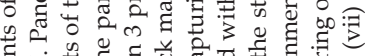

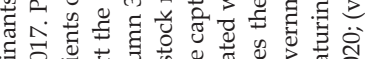

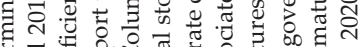
चี

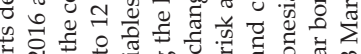
กิ 원

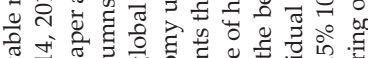
Ð

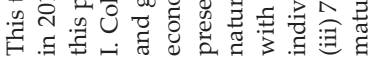

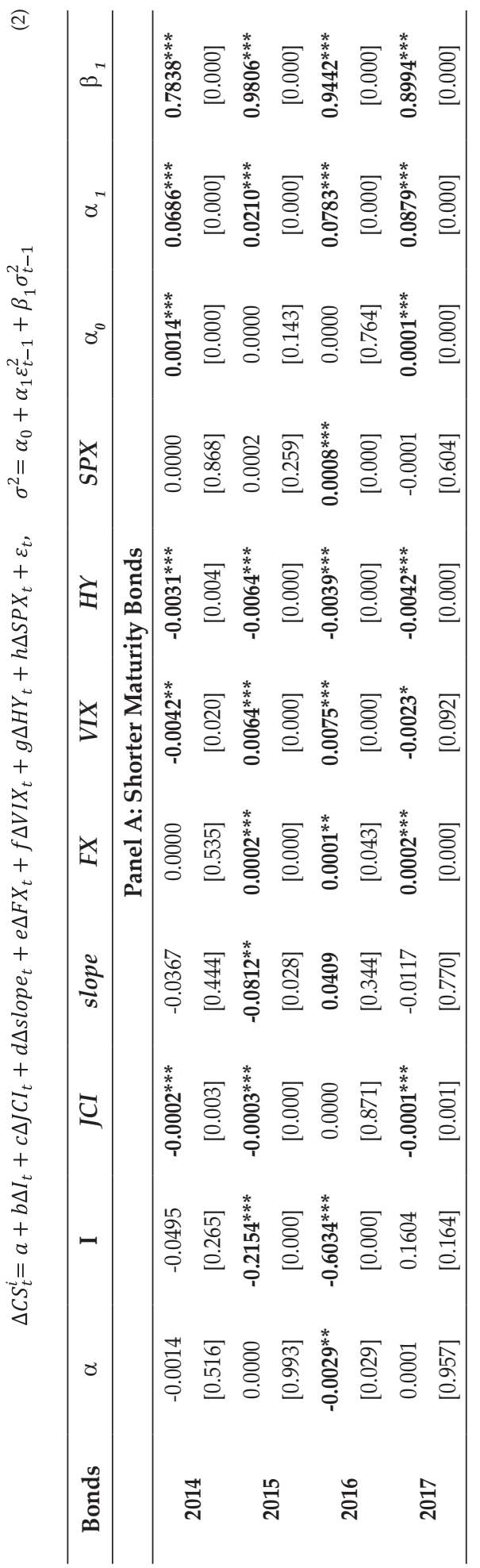




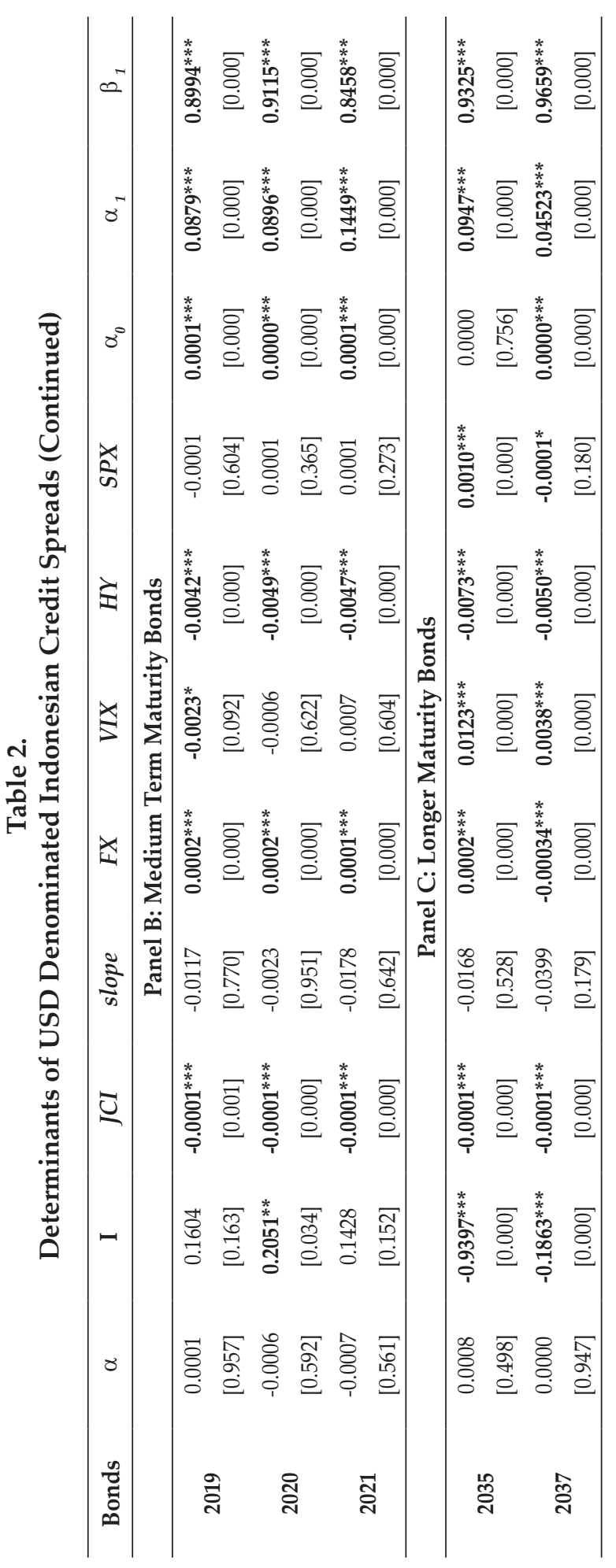


We now turn our attention to the variables that capture the uncertainty associated with the US equity market. It is clear that all four shorter-maturity bonds are highly responsive to the VIX and gauge uncertainty in the US equity market with mixed coefficient signs. For example, the default spreads of the bonds maturing in 2014 and 2017 are negatively related to the VIX. This implies that the default spread narrows as US equity market uncertainty rises. On the other hand, the spread associated with the bonds maturing in 2015 and 2016 are positively related to the VIX, implying widening of the spread as uncertainty in the US equity market rises. Similarly, the spreads associated with all four bonds are highly responsive to changes in the high yield index, with a negative sign attached to all coefficients. This implies that, as the high yield index rises, the spreads narrow, implying that, as the risky high yield world index rises, the performance of risky bonds issued by Indonesia increases as well, by way of tightening of the spread. As for the US equity market used as the independent variable, only one bond responds in this category for any changes in the index, an indicator of investor willingness to accommodate more risk.

A2 Medium-maturity bonds: Panel B of Table 2 reports the results for bonds of medium maturity, with three USD-denominated government bonds falling under this category, maturing in 2019, 2020, and 2021. The interest rate factor reported in the third column is significant only for the 2020 bond and the spreads of the other two bonds, maturing in 2019 and 2021, are not responsive to the interest rate factor. The sign associated with this variable is positively related to the spread, implying that a rise in the risk-free rate widens the spreads. This is the only inconsistent sign for this variable in the entire sample and it is inconsistent with a theoretical explanation. The asset factor reported in the fourth column is significant for all three bonds in this category. Consistent with theory, the signs of the coefficients are all negative, implying that an increase in the value of the issuer narrows the bond spread. The slope of the yield curve reported in the fifth column is not significant for any of the medium-term bonds. The exchange rate variable, however, is significant for all three bonds, signalling adverse effects on the country's economy. The VIX matters only for the 2019 maturity bond with the negative sign. As the case for shorter-maturity bonds, the spreads associated with all three bonds respond to changes in the high yield bond index, implying a rise in appetite for risky bonds. None of the bonds in this category are responsive to changes in the US equity market index.

A3 Longer-maturity bonds: The results reported in Panel C of Table 2 show two bonds in the longer-maturity category, maturing in 2035 and 2037. The asset factor and the interest rate factor are highly significant, with correct signs implied by theory for these two popular determinants. Notably, the interest rate factor is statistically and economically significant for the longer-maturity bonds. However, the slope variable is not significant. The exchange rate variable is highly significant for both bonds, but, unlike the other bonds in the sample, the yield spread for the bond maturing in 2037 has a negative coefficient, implying narrowing of the spread as the exchange rate appreciates. The VIX is positively related to the spread, implying a rise in uncertainty in the US market widens the spreads for risky longmaturity bonds issued by the Indonesian government. 

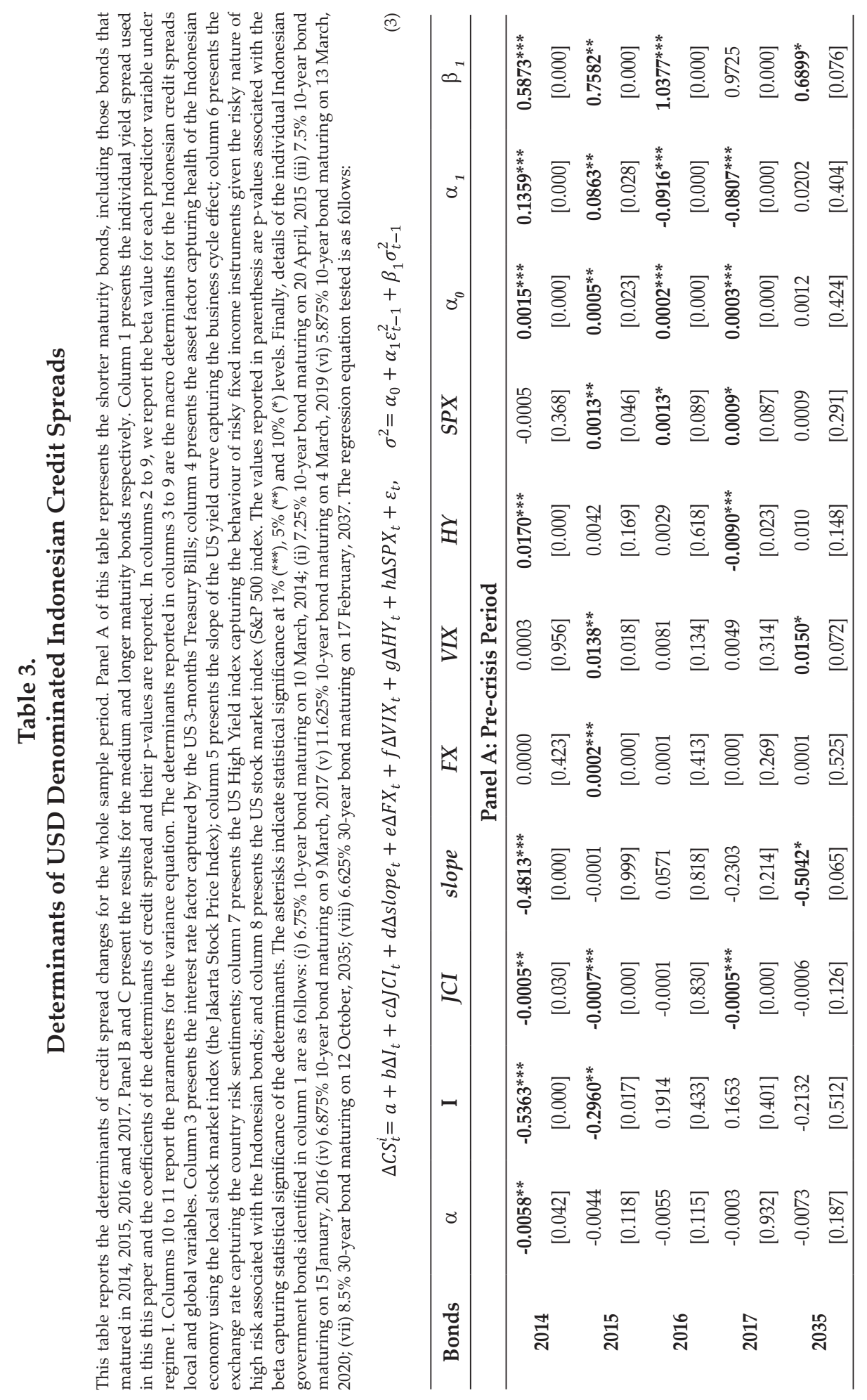


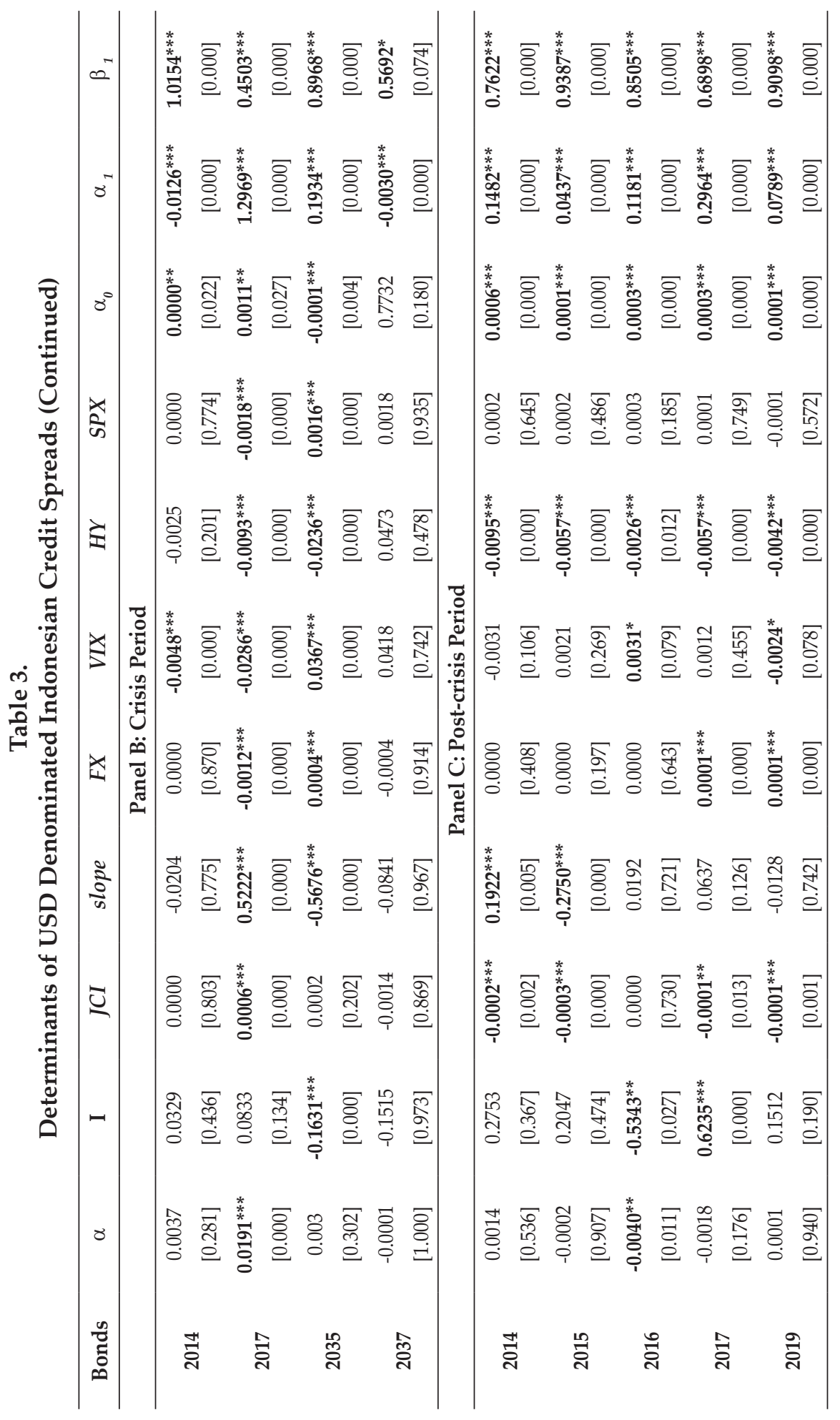




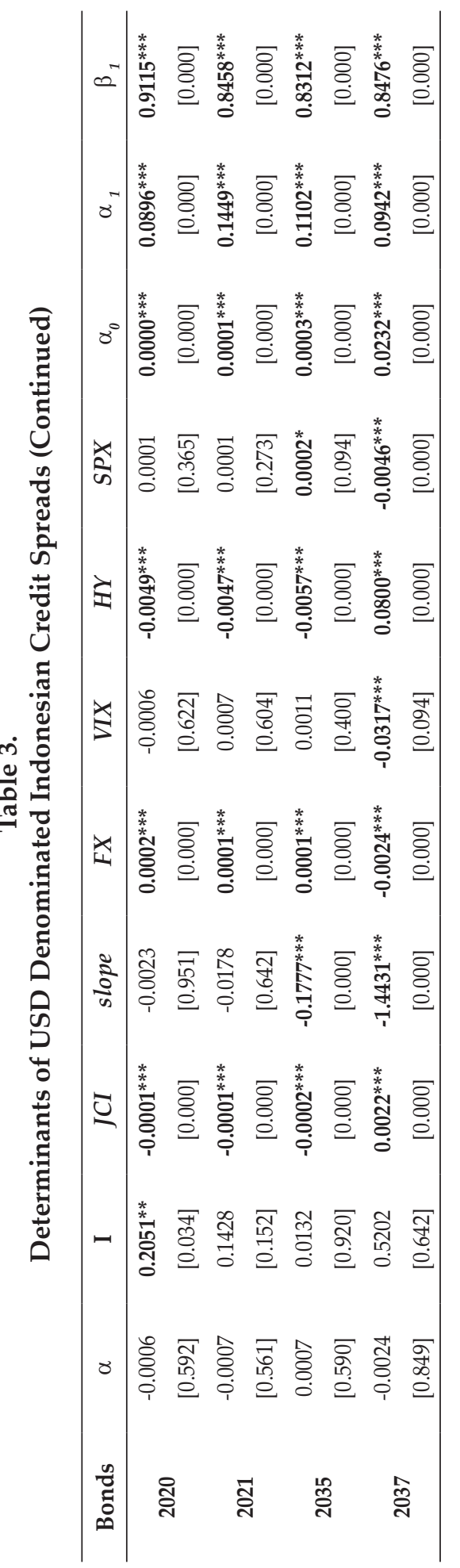




\section{B. Credit Spread Determinants Accounting for the Global Financial Crisis}

The results discussed above assume that the Global Financial Crisis (GFC) had no bearing on the results. To see how the results change, it is important to account for the GFC's effects and we therefore partition our sample into three periods, covering the pre-GFC crisis window, the crisis window, and the post-crisis window, the results reported in Panels A to C, respectively. For individual bonds, the following dates are used to create windows capturing the pre-crisis, crisis, and post-crisis periods, as follows: the pre-crisis break date is 27 February 2007, the crisis window starts 27 February 2007 and ends 30 December 2009, and the post-crisis window starts 31 December 2009. This study follows the justification of Narayan et al. (2004) to create data subsamples with these three windows and Panels A to C, respectively, of Table 3 report the results for these windows, identified above for individual bonds.

B1 Pre-crisis window: Based on the results, it is clear that the interest rate and asset factors are dominant for the shorter-maturity groups along with the US stock market index. Results in the pre-crisis window could not be generated for the 2019, 2020, 2021, and 2037 maturity bonds due to insufficient observations. The slope variable and the VIX are significant for the longer-maturity bond maturing in 2037.

B2 Crisis-window: The shorter-maturity bond maturing in 2014 hardly relates to any of the fundamentals that theoretically determine credit spreads, except for the VIX. On the other hand, the credit spreads of the bonds maturing in 2017 and 2035 respond to almost all the determinants, whereas the credit spread of the bond maturing in 2037 is hardly responsive to any of the determinants covered in this study.

B3 Post-crisis window: For the shorter-maturity category, the asset factor, the slope factor, and the high-yield index significantly influence the credit spread. For the medium-maturity category, the asset factor, the exchange rate factor, and the high-yield index are the dominant determinants. On the other hand, except for the interest rate factor, almost all of the determinants are significant. Notably, the slope variable is statistically and economically highly significant.

Overall, our analysis partitioning the data into pre-crisis, crisis, and post-crisis windows in terms of maturities and sample windows produces heterogeneous reactions. Intra-group behaviour is also somewhat different when we split the sample and conduct the analysis. During the crisis period, the local stock market index, representing the asset factor, is hardly relevant for any of the spreads, except the 2017 bond spread. On the other hand, as predicted, the high yield index, which is closely related to risky emerging market bonds, turns out to be a stronger determinant of spread behaviour. The other global variables also seem to be influential, given the nature of the crisis in 2007-2008. On the other hand, the pre-crisis results are similar to those for the entire sample for the shorter-maturity category. However, for the longer-maturity bond, the slope factor and the VIX factor are influential variables. The post-crisis results convey a clearer picture of the determinants of spreads in this study. The asset factor, the exchange rate factor, and the high yield index are the dominant variables across all maturities. Almost all of the coefficients of the lagged squared error and the lagged conditional variance are highly significant, with the sum of the coefficients of these two being very close unity, an indication that shocks to the conditional variance are highly persistent. 


\section{CONCLUSION}

This paper investigates the credit spreads on USD-denominated government bonds issued by Indonesia. The determinants implied by the structural models of default are highly relevant in pricing the risky government bonds issued by Indonesia. Notably, local variables such as the asset factor and exchange rate variables are relevant across different maturities. The high yield index is the most dominant global determinant - an asset class that resonates well with the emerging risky government bond market - along with the VIX for the credit spreads on these government bonds. The US stock market index is weakly linked to these spreads across the board.

Regarding the shorter- and medium-maturity bonds, there is evidence of heterogeneity among the responses of individual spreads to the local and global determinants. Regarding the spreads associated with the longer-maturity bonds, there is evidence of a systematic response to all the variables, except for the slope variable.

When the analysis is conducted separately for different windows accounting for the GFC, a clearer picture emerges during the post-crisis period, with distinct evidence of the importance of major determinants across different maturities. Overall, it can be concluded that the Indonesian credit spreads of international bonds respond to the major determinants implied by the structural models of default.

Given the disaggregated nature of our analysis, this paper provides evidence of heterogeneous responses captured through a bond-by-bond analysis. The subsample analysis demonstrates this behaviour, with overall evidence maintaining the efficacy of risky debt pricing its sensitivity to the major determinants implied by structural models of default. These results are consistent with previous studies, such as those of Longstaff et al. (2011), Riddle et al. (2013) and Thuraisamy et al. (2008).

\section{REFERENCES}

Augustin, P. (2018). The Term Structure of CDS Spreads and Sovereign Credit Risk Journal of Monetary Economics, 96, 53-76.

Avramov, D., Jostova, G., and Philipov, A. (2007). Understanding Changes in Corporate Credit Spreads. Financial Analysts Journal, 63, 90-105.

Bank for International Settlements (BIS). (2003). Quarterly Review.

Batten, J.A., Fetherston, T.A., and Hoontrakul, P. (2006). Factors Affecting the Yields of Emerging Market Issuers: Evidence from the Asia-Pacific region. Journal of International Financial Markets, Institutions and Money, 16, 57 - 70.

Claessens, S., and Pennacchi, G. (1996). Estimating the Likelihood of Mexican Default from the Market Prices of Brady Bonds. Journal of Financial and Quantitative Analysis, 31, 109-126.

Collin-Dufresne, P., Goldstein, R., and Martin, S. (2001). The Determinants of Credit Spreads Changes. Journal of Finance, 56, 2177-2207.

Hilscher, J., and Nosbusch, Y. (2010). Determinants of Sovereign Risk: Macroeconomic Fundamentals and the Pricing of Sovereign Debt*. Review of Finance, 14, 235-262. 
Longstaff, Francis A., Jun Pan, Pedersen, L. H., and Singleton, Kenneth J. (2011). How Sovereign Is Sovereign Credit Risk? American Economic Journal: Macroeconomics, 3, 75-103.

Longstaff, F.A., and Schwartz, E.S. (1995). A Simple Approach to Valuing Risky Fixed and Floating Rate Debt. The Journal of Finance, 50, 789-819.

Merton R.C. (1974). On the Pricing of Corporate Debt: The Risk Structure of Interest Rates. Journal of Finance, 29, 449-70.

Narayan, P. K., Sharma, S. S., and Thuraisamy, K. S. (2014). An Analysis of Price Discovery from Panel Data Models of CDS and Equity Returns. Journal of Banking \& Finance, 41, 167-177.

Riedel, C., Thuraisamy, K. S., and Wagner, N. (2013). Credit Cycle Dependent Spread Determinants in Emerging Sovereign Debt Markets. Emerging Markets Review, 17, 209-223. 